9 Modan B, Lillienfield AM. Polycythaemia vera and leukaemia. Medicine 1965;44:305-44.

${ }^{10}$ Ho-Yen DO, Slidders W. Bone marrow cellularity assessed by point-counting. J Clin Pathol 1978;31:753-6.

" Ho-Yen DO, Saleem N, Fleming LW, Stewart WK, Goodall HB. Bone marrow cellularity and iron stores in chronic renal failure. Acta Haematol 1980;64:265-70.

\section{Staining modification of creatine kinase isoenzyme method}

Following the publication of $A C P$ Broadsheet $106^{1}$ in which I described a fluorescence method for the detection and measurement of creatine kinase isoenzymes following cellulose acetate electrophoresis, I have been asked if the method could be adapted to isoenzyme staining by the tetrazolium reduction technique. This can be readily achieved by the addition of $2.5 \mathrm{mg}$ of nitro blue tetrazolium (NBT), and of $0.025 \mathrm{mg}$ of phenazine methosulphate (PMS) or Meldola's blue-for example, $25 \mu \mathrm{l}$ of a freshly prepared aqueous solution of concentration $1 \mathrm{mg}$ per m-to each $2.5 \mathrm{ml}$ of the double strength enzyme substrate (reagent 2) immediately prior to its mixture with $2.5 \mathrm{ml}$ agar (reagent 3 ). Incubation of the cellulose acetate membrane with the modified substrate-agar mixture is then carried out in the dark in a moist chamber for one hour, following which the membrane is rinsed for one minute in a 5\% $\mathrm{vol} / \mathrm{vol}$ aqueous dilution of acetic acid, rinsed for a further one minute in distilled water and dried between absorbent paper under pressure.

The staining procedure is of comparable sensitivity to the fluorescence method with a detection limit approximately $3 \mathrm{U} / \mathrm{h}$ at $30^{\circ} \mathrm{C}\left(5 \mathrm{U} / 1\right.$ at $\left.37^{\circ} \mathrm{C}\right)$. It takes longer to complete because the incubation time is one hour, but has the advantage of yielding semi-permanent stained bands which can be densitometrically scanned in the visible rather than the UV range. Direct comparison of the two methods on isoenzyme mixtures has demonstrated that the relative proportions (recoveries) of each isoenzyme fraction are identical with both the staining and the UV procedure. Meldola's blue is a more stable electron carrier than the frequently used PMS and produces slightly less background colour.

SIDNEY B ROSALKI

Department of Chemical Pathology, Royal Free Hospital, Pond Street,

Hampstead, London, NW3 $2 Q G$
The assistance of Miss A Y Foo in the evaluation of this modification is gratefully acknowledged.

\section{Reference \\ ' Rosalki SB. Creatine kinase isoenzyme demonstration and measurement. $\boldsymbol{A C P}$ Broadsheet 106, 1982.}

\section{Book reviews}

Children with Sex Chromosome Aneuploidy: Follow-Up Studies. March of Dimes Birth Defects Foundation. Birth Defects: Original Article Series, Vol 18, no 4, 1982. Ed Donald A Stewart. (Pp 251; £41.) Alan R Liss Inc. 1982.

This book records the proceedings of a conference, held in Toronto, of those involved in a long term multicentre study, commenced in 1964, of children identified at birth as having sex chromosome aneuploidy.

An opening editorial chapter helpfully summarises the findings. Progress reports from the two largest study groups, Denver and Edinburgh, complement one another in that the former includes nine children with $45 \mathrm{X}$ Turner's syndrome or its variants whilst the latter has a larger number of 47 XYY boys. Reports follow from the smaller study groups and there is a concluding discussion of ethical and legal issues.

The main conclusions are that $47 \mathrm{XXY}$ and $47 \mathrm{XYY}$ boys and $47 \mathrm{XXX}$ girls all tend to be tall; to have a mildly depressed mean, especially verbal, IQ and impaired school achievement. Short stature is confirmed for Turner's syndrome but lowered intelligence is questionable. No consistent pattern of behavioural disturbance emerges apart from excess negativity and temper tantrums among $47 \mathrm{XYY}$ boys in Edinburgh.

Regrettably the publishers do not disclose when the conference was held.

M d'A CRAWFORD

Endotoxins and their Detection with the Limulus Amebocyte Lysate Test. Progress in Clinical and Biological Research. Vol 93. Ed Stanley W Watson, Jack Levin and Thomas J Novitsky. (Pp 417; £35.) Alan R Liss Inc. 1982.

This is an account of the Proceedings of an International Conference on Endotoxin Standards and the Limulus Amebocyte Lysate Test held at Massachusetts in September 1981 .
The Limulus Test is not used as a routine in Britain and there is considerable debate about its place in clinical laboratory practice. This collection of papers will be useful to anyone with an interest in possible applications of the Limulus Test and to anyone concerned with the difficult field of pyrogen tests and pyrogenic substances.

The Proceedings of a wide-ranging conference such as this tend to vary in quality of presentation and content. In addition, there is variation in the type face of different papers in this volume. The verbatim accounts of the verbal exchanges at the meeting may include some useful information, but this approach is expensive and inelegant and should be abandoned in favour of the services of someone who can write a succinct and more helpful account of such exchanges.

There is a mass of information in this book. It is less likely to be of interest to clinicians than to those who are technically involved in various areas of pathology, pharmacology and microbiology. It will certainly be of interest to those concerned with the detection and measurement of endotoxins and pyrogens. At $£ 35$ this collection of papers is rather expensive.

JG COLLEE

Tumors of the Soft Tissues. Atlas of Tumor Pathology 2nd series. Fascicle 1/Revised. Raffaele Lattes. (Pp 264; \$14.) Armed Forces Institute of Pathology. 1982.

One of the editorial "perks" is first choice of the books to review and some restraint is needed so as not to be selfish. However, restraint was cast aside for this revised version of the AFIP Fascicle on "Tumors of the Soft Tissues" and I carried it off to my laboratory with pleasure. This book should be on the shelf of every histologist with responsibility for reporting soft tissue lesions. The format is as before but expanded to take account of subjects previously dealt with inadequately or not at all. The presentation is even throughout, the photographs are excellent. I particularly enjoyed the section on malignant fibrous histiocytoma.

There are numerous electron micrographs to support the classical histology but it is a pity, though understandable, that immunofluorescent and immunoperoxidase techniques are omitted. The second edition Fascicle on CNS tumours has already been followed by a brief supplement. It would be very helpful if that precedent could be followed for soft tissue 
tumours with particular reference to the investigation of what are often difficult diagnoses by immune techniques.

G SLAVIN

Antibiotics of the Beta-Lactam Group. D Greenwood (Pp 84; £8.95.) John Wiley \& Sons Limited. 1982.

This very readable short review of the Beta-Lactam antibiotics is the second of a series from this publisher designed to allow a well chosen individual the opportunity to offer a distillation of his experience and knowledge of a subject without the need to cover it to total exhaustion. Dr Greenwood's interest in the action of antibiotics on bacterial cells is well known, and his natural enthusiasm in this study is evident in the text. It is clear and succinct, and should appeal to a wide spread of readers of different degrees of knowledge of the subject. It could be a painless introduction to a student faced with this large and growing group of antibiotics, but at the same time it contains information and views of more esoteric interest. The six chapters deal with development, the response of bacteria, their action, resistance, interaction, and the therapeutic use of the BetaLactams.

There are a number of illustrations, some of high quality, some bibliography, and a good index. I would have preferred a more traditional typeface to the typewritten style offered.

\section{Some new titles}

GL GIBSON

The receipt of these books is acknowledged and this listing must be regarded as sufficient return for the courtesy of the sender. Books that appear of particular interest will be reviewed as space permits.

Pathology of Tumours in Laboratory Animals. Vol 3. Tumours of the Hamster. IARC Scientific Publications no. 34. (Pp 461; US\$ 40; Sw fr 80.) World Health Organisation. 1982.

Cancer Incidence in Five Continents. Vol IV. IARC Scientific Publications no. 42. Ed J Wat-rhouse, C Muir, $K$ Shanmugaratnam and J Powell. (Pp 812; Sw fr 100 ; US\$ 50.00). World Health Organisation. 1982.

Prevent Infection. Translated by WC Noble. (Pp 106; paperback £3.75.) William Heinemann Medical Books Ltd., 1983.

1982 Year Book of Cancer. Ed RL Clark, RW Cumley and RC Hickey. (Pp 477; £33.) Year Book Medical Publishers Inc. 1982.

\section{Notices}

Technology impact: new directions in laboratory medicine

In recent years rapid progress has been made in understanding the biochemical and molecular biological pathogenesis of disease processes. Because of this expansion in our ability to diagnose and monitor human disease, new approaches to disease prevention and therapy are now emerging.

The conference will draw together physicians (cardiologists, allergists) and analytical scientists (clinical chemists, biomedical engineers) to present and discuss information critical to the development of new directions and applications of diagnostic monitoring.

This conference will be held 21-23 September 1983 at the Barbizon-Plaza Hotel, New York City.

For further information, contact: Con- $\frac{\bar{\sigma}}{\partial}$ ference Department, The New York $\varrho$ Academy of Sciences, 2 East 63rd Street, New York, NY 10021.

Expression of results of haemoglobin determinations

On the occasion of the Congresses of the International Society of Haematology and $\underset{\omega}{\omega}$ the International Society of Blood Transfusion in Budapest (August 1982), the Board 2 and the General Assembly of the Interna- 음 tional Committee for Standardization in Haematology approved the following
resolution:

"In physiological, biochemical or $\vec{\ominus}$ metabolic studies expressing results of haemoglobin determination as amount of $\omega$ substance is acceptable, but for classification, diagnostic and/or therapeutic purposes the continued use of mass con- $\frac{\partial}{\partial}$ centration is recommended. However, for the sake of uniformity in reporting it may $\frac{}{\Phi}$ be useful to include also the result expressed as amount of substance.

When $\mathrm{Hb}$ is reported as mass concentra- 3 tion it should be expressed in $\mathrm{g} / \mathrm{l}$. When reported as substance concentration the elementary entity should be defined as the haemoglobin monomer, and clearlyo specified in the component name-for $\bar{O}$ example, $\mathrm{Hb}(\mathrm{Fe}), \mathrm{HbCO}(\mathrm{Fe}), \mathrm{MCH}(\mathrm{Fe})$." 